\title{
Effects of methyl isocyanate on rat muscle cells in culture
}

\author{
DIANA ANDERSON, ' SHOBHA GOYLE, ${ }^{2}$ B J PHILliPS, ' A TEE, ' LINDA BEECH,' \\ W H BUTLER' \\ From the British Industrial Biological Research Association, ${ }^{\prime}$ Carshalton, Surrey SM5 4DS, UK, and School of \\ Life Sciences, ${ }^{2}$ Jawaharlal Nehru University, New Delhi, India
}

\begin{abstract}
Since the Bhopal disaster, in which the causal agent was methyl isocyanate (MIC), exposed people have complained of various disorders including neuromuscular dysfunction. In an attempt to gain some information about the response of muscle tissue to MIC its effects were investigated in cells in culture isolated from muscle of 2 day old rats. After treatment with a range of MIC concentrations ( $0.025-0.5 \mu \mathrm{l} / 5 \mathrm{ml}$ culture) the total number of nuclei of the two main cell types (fibroblasts and myoblasts) and the number of nuclei in muscle fibres (myotubes) were recorded. At lower doses which had little effect on the total number of nuclei, the formation of muscle fibres-that is, fusion of muscle cells - was prevented as the proportion of nuclei in myotubes was decreased. At higher doses both cell types were killed. This would suggest either an effect on muscle differentiation or a selective toxicity towards myoblasts. The observations were supported by light and electron microscopy.
\end{abstract}

In the industrial disaster in Bhopal, India, in 1984 the leakage of 40 tons of methyl isocyanate (MIC) gas from a pesticide plant claimed over 2500 lives and left an estimated 15000 people suffering from a variety of ailments. Three months later 50000 of the people continued to have disorders of the lungs and eyes and ulceration of the gastrointestinal tract and many complained of kidney, liver, and neuromuscular dysfunction.' Since then, various researchers have been gathering toxicological information.

Kimmerle and Eben showed that MIC was highly irritant to skin and mucosae and produced pulmonary oedema. ${ }^{2}$ Nemery et al suggested that MIC at high concentrations probably caused peracute death through reflex inhibition of breathing and rats surviving exposure exhibited narrowing of the airways and haemorrhagic pulmonary oedema. ${ }^{3}$ The lesions were repaired rapidly but renewed inflammation and peribronchial fibrosis were apparent. Nemery et al also showed that cyanide intoxication is not concerned in the clinical syndrome seen after exposure to MIC nor does sodium thiosulphate protect rats from the acute and subacute effects of MIC. ${ }^{4}$ Cellular immunity has

Accepted 6 April 1987 been shown to be slightly compromised by exposure to MIC. ${ }^{5}$

In investigations of the genotoxic potential of MIC it has been reported to be non-mutagenic in the standard Ames $^{6}$ and preincubation assay, ${ }^{7}$ and Anderson et al showed that negative results were also obtained in the Ames test when urine from animals treated with MIC was tested. ${ }^{8}$ Shelby et al have also reported a negative sex linked recessive lethal test in Drosophila. ${ }^{7}$ Positive results have been shown, however, for point mutation in the mouse lymphoma assay and in Chinese hamster ovary cells in culture for chromosome aberrations and sister chromatid exchange in the absence of rat liver S9. In vivo there was marginal evidence of an effect for chromosome aberrations and sister chromatid exchanges in the $\mathrm{B}^{6} \mathrm{C}_{3} \mathrm{~F}_{1}$ hybrid mouse but results were not reproducible. ${ }^{7}$ The results from the bioassay using the same strain are eagerly awaited since they would give an indication of the potential carcinogenicity of MIC in man.

In man there have been complaints of neuromuscular dysfunction' but little or nothing is known about the toxicology of such effects. In an attempt to gain some information on muscular function we examined the effect of MIC administered to rat muscle cells in culture. 


\section{Materials and methods}

\section{ISOLATION OF MUSCLE CELLS CULTURE TECHNIQUES}

Cells were isolated from muscle of 2 day old rats by treatment with dispase solution. Cells were cultured in Dulbecco's medium with $10 \%$ fetal calf serum in 25 $\mathrm{cm}^{2}$ flasks and placed in a $\mathrm{CO}_{2}$ gassing incubator at $37^{\circ} \mathrm{C}$ until treatment.

\section{TREATMENT REGIMEN}

MIC was added directly to the flasks and left for two hours and then replaced by fresh medium. Flasks were then incubated until fixation.

\section{EXPERIMENTAL APPROACHES}

Various experimental protocols were used. The first study with treatments on days 1 and 2 was to determine a suitable range of doses for the final study in which the compound was administered at days 2, 4, and 6 in culture in order to treat the myoblasts at different stages of development.

\section{CELL FUSION COUNTS ON STANDARD CULTURES}

Counts were made on 10 fields for each culture. The total number of nuclei of all cell types and the number of nuclei in myotubes was recorded.

\section{Results}

STUDY 1

In the first study (doses/ml:0·25, $0 \cdot 5,1$, and $2 \mu$ treated at day 1 and fixed at day 9) only cultures with $0.25 \mu \mathrm{l}$ MIC had any cells (data not shown).

In those cultures treated on day 2 with lower dose treatments and fixed at day 9 there was little effect on total nuclei but myotube formation was much reduced at 0.25 and $0.083 \mu \mathrm{l}$ (table 1$)$.

Table 1 Study 1: the effect of MIC treatment on day two of culture on the growth and fusion of rat muscle cells (fixed on day nine)

\begin{tabular}{llll}
\hline $\begin{array}{l}\text { MIC } \\
(\mu l / 5 \text { ml culture) })\end{array}$ & $\begin{array}{l}\text { Total nuclei } \\
\text { per culture }\end{array}\left(10^{6}\right)$ & $\begin{array}{l}\text { Nuclei in } \\
\text { myotubes }\left(10^{6}\right)\end{array}$ & \% Fusion \\
\hline 0 & 3.40 & 0.51 & 15.0 \\
0.009 & 3.83 & 0.57 & 14.9 \\
0.028 & 3.70 & 0.40 & 10.8 \\
0.083 & 2.85 & 0.00 & 0.0 \\
0.25 & 2.88 & 0.03 & 1.0
\end{tabular}

${ }^{\mathrm{a} C a l c u l a t e d}$ from counts made on 10 representative microscope fields per culture using duplicate cultures.

$\%$ Fusion $=\frac{\text { Nuclei in myotubules }\left(10^{6}\right)}{\text { Total nuclei per culture }} \times 100$

To achieve these low concentrations, MIC was dissolved in culture medium and then diluted.
Table 2 Study 2: the effect of MIC treatment at various times after culture establishment (day 0) on the growth and fusion of rat muscle cells

\begin{tabular}{|c|c|c|c|c|}
\hline $\begin{array}{l}\text { Day of } \\
\text { treatment }\end{array}$ & $\begin{array}{l}\text { MIC } \\
(\mu l / 5 \mathrm{ml} \\
\text { culture })\end{array}$ & $\begin{array}{l}\text { Total nuclei } \\
\text { per culture } \\
\left(10^{6}\right)\end{array}$ & $\begin{array}{l}\text { Nuclei in } \\
\text { myotubes } \\
\left(10^{6}\right)\end{array}$ & $\%$ Fusion \\
\hline $1^{c}$ & $\begin{array}{l}0 \\
0.025 \\
0.05 \\
0.125 \\
0.25 \\
0.5\end{array}$ & $\begin{array}{l}2.76 \\
3.11 \\
2.79 \\
2.43 \\
2.01^{*} \\
0.0^{*}\end{array}$ & $\begin{array}{l}0.36 \\
0.24 \\
0.28 \\
0.12 \\
0.04 \\
0.0\end{array}$ & $\begin{array}{r}13.0 \\
7.7 \\
10.0 \\
4.9^{*} \\
2.0^{*} \\
0.0^{*}\end{array}$ \\
\hline $4^{d}$ & $\begin{array}{l}0 \\
0.025 \\
0.05 \\
0.125 \\
0.25 \\
0.5\end{array}$ & $\begin{array}{l}2.89 \\
2.46 \\
3.15 \\
2.15 \\
2.65 \\
0.0^{*}\end{array}$ & $\begin{array}{l}0.51 \\
0.36 \\
0.64 \\
0.02 \\
0.02 \\
0.0\end{array}$ & $\begin{array}{c}17.6 \\
14.6 \\
20.3 \\
0.9^{*} \\
0.8^{*} \\
0.0^{*}\end{array}$ \\
\hline $6^{d}$ & $\begin{array}{l}0 \\
0.025 \\
0.05 \\
0.125 \\
0.25 \\
0.5\end{array}$ & $\begin{array}{l}2 \cdot 89 \\
3 \cdot 37 \\
0 \cdot 59^{*} \\
0 \cdot 0^{*} \\
0 \cdot 0^{*} \\
0 \cdot 0^{*}\end{array}$ & $\begin{array}{l}0.51 \\
0.70 \\
0.02 \\
0.0 \\
0.0 \\
0.0\end{array}$ & $\begin{array}{c}17 \cdot 6 \\
20 \cdot 8 \\
3 \cdot 4^{*} \\
0 \cdot 0^{*} \\
0 \cdot 0^{*} \\
0 \cdot 0^{*}\end{array}$ \\
\hline
\end{tabular}

c Fixed on day 5.

d Fixed on day 8.

Footnotes as for study 1 .

${ }^{*} \mathrm{p}=<0.05$ (values compared with control means).

STUDY 2

The results for control cultures were similar to those in the first study with mean values of $2.76 \times 10^{6}$ nuclei (13.0\% fused) on day 5 and $2.89 \times 10^{6}(17.6 \%$ fused $)$ on day 8 (table 2). Because of the larger number of control cultures in this study it was possible to observe the variation obtained with this counting method. The total nuclei were relatively consistent (a range of 2.27 to $\left.3.48 \times 10^{6}\right)$ but fusion was more variable $(8.1$ to $25 \cdot 6 \%$ ).

With treatment on day 1 , nuclear counts were significantly reduced at $0 \cdot 25 \mu \mathrm{l}$ (more than two standard deviations below the control mean) and fusion was significantly lower at both 0.25 and $0.125 \mu \mathrm{l}$ in cultures fixed on day 5 . No cells were present after treatment with $0.5 \mu \mathrm{l}$.

After treatment on day 4 and fixation on day 8 total counts were similar to controls at doses up to $0.25 \mu \mathrm{l}$ but fusion was inhibited at 0.125 and $0.25 \mu$ l. There were no cells present after treatment with $0.5 \mu \mathrm{l}$.

Treatment on day 6 resulted in a decrease in nuclear counts and fusion at a dose of $0.05 \mu \mathrm{l}$ and cells were destroyed at higher concentrations.

\section{MICROSCOPY}

On days 4 and 6 at the light microscope level the control cultures consisted of a mixed population of long strap-like multinucleate muscle cells and mononucleated spindle cells resembling fibroblasts (fig 1). The fibroblasts showed many fatty cytoplasmic vacuoles while both fibroblasts and muscle cells had dense cytoplasmic inclusions. At the electron microscope level two cell types could be readily identified by 


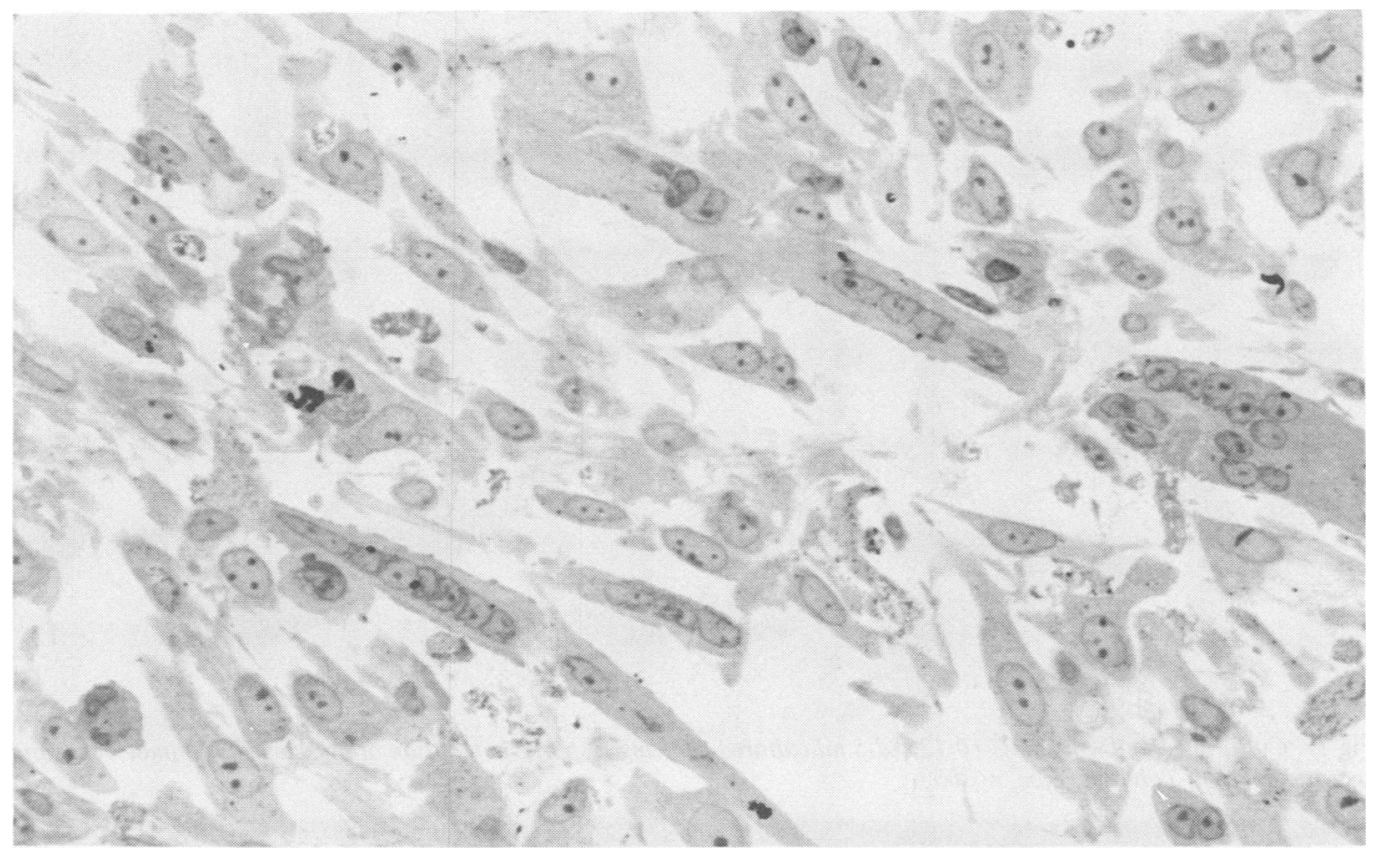

Fig 1 Control culture showing a mixed population of syncytial strap-like muscle cells and spindle fibroblasts. (Toluidine blue $\times 300$ ).

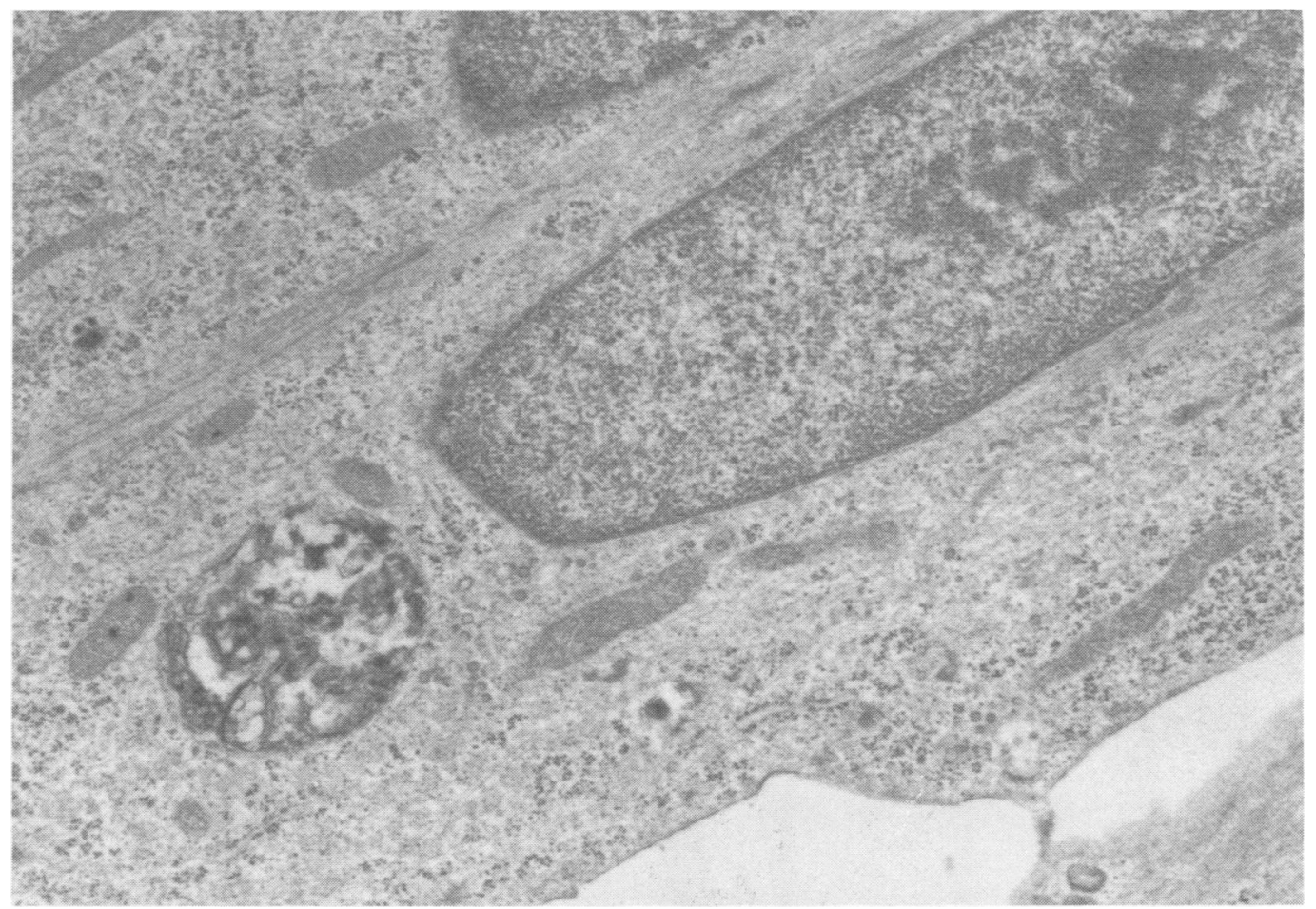

Fig 2 Electron micrograph of a control muscle cell showing well organised fibrils and an autophagic vacuole. $(\times 15000)$. 


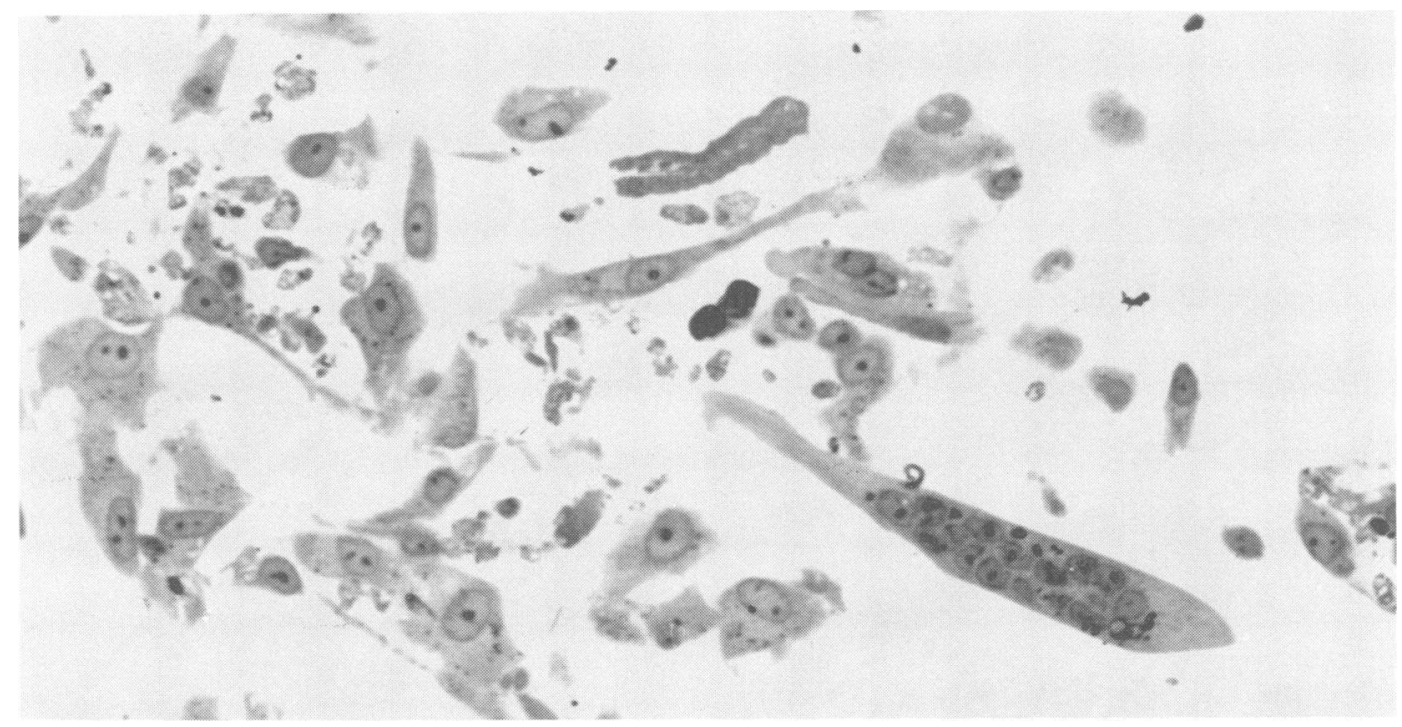

Fig 3 Culture treated with MIC $(0 \cdot 125 \mu \mathrm{l} / 5 \mathrm{ml}$ culture $)$ showing a sparse population of muscle cells, spindle cells, and necrotic debris. (Toluidine blue $\times 300$ ).

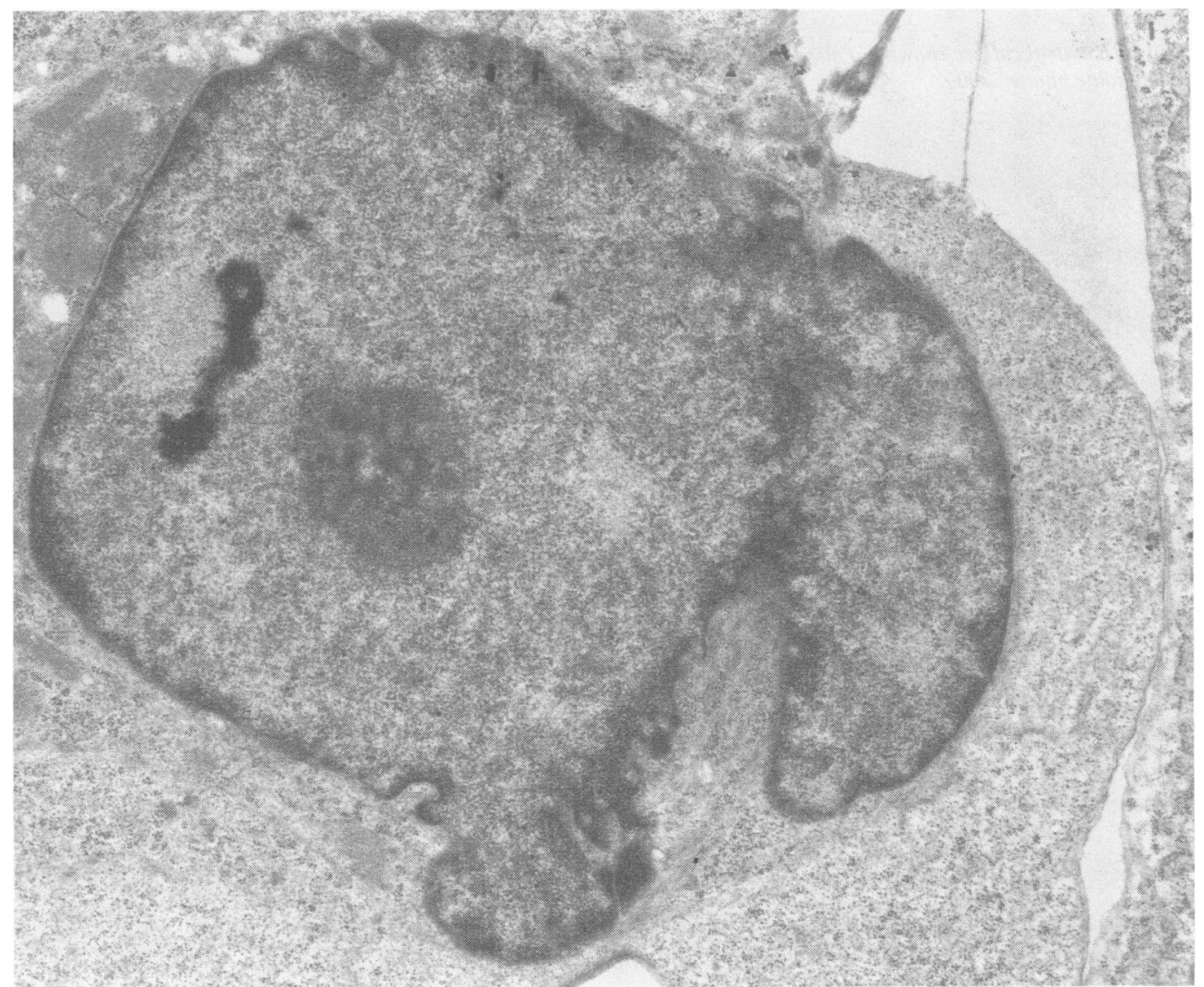

Fig 4 Electron micrograph of a culture treated with MIC $(0 \cdot 125 \mu \mathrm{l} / 5 \mathrm{ml}$ culture $)$ showing a muscle cell with a simplified profile and part of a normal fibroblast. $(\times 20000)$. 


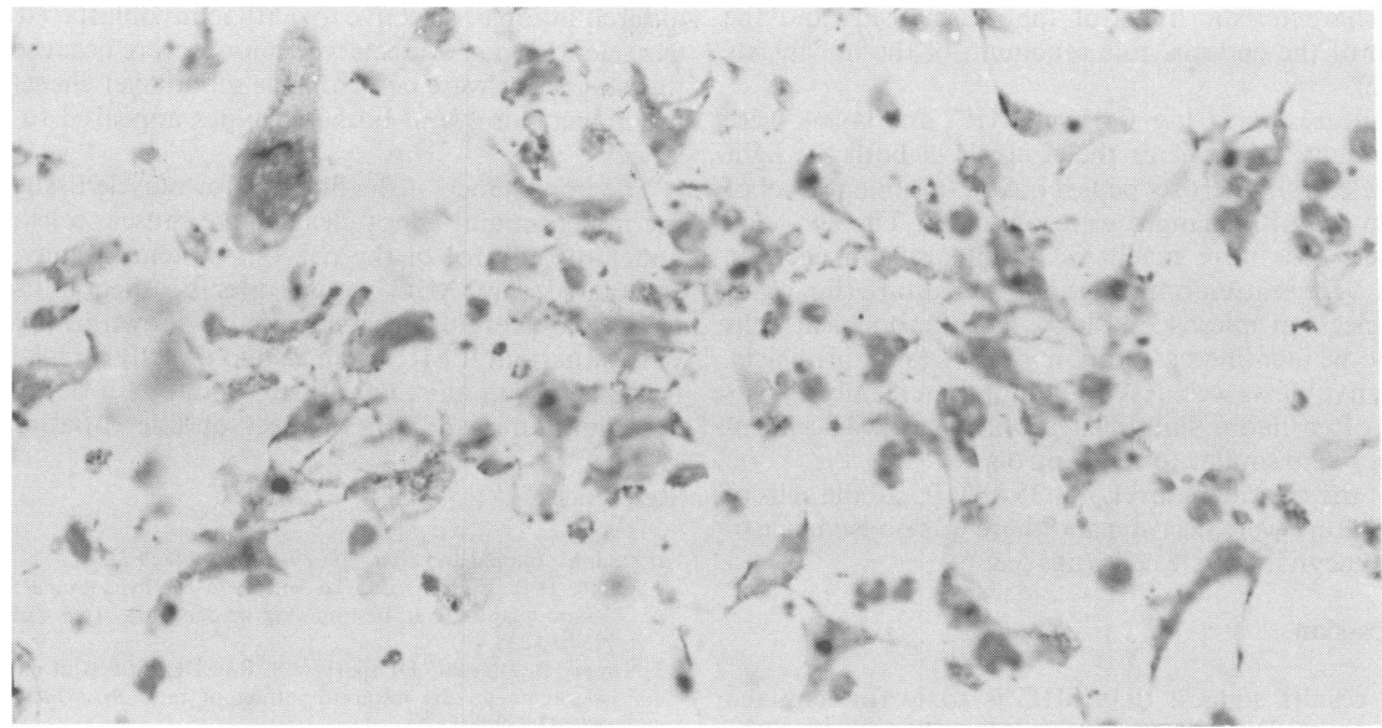

Fig 5 Culture treated with MIC $(0 \cdot 25 \mu l / 5$ ml culture) showing necrotic cells and no intact muscle cells. (Toluidine blue $\times 300$ ).

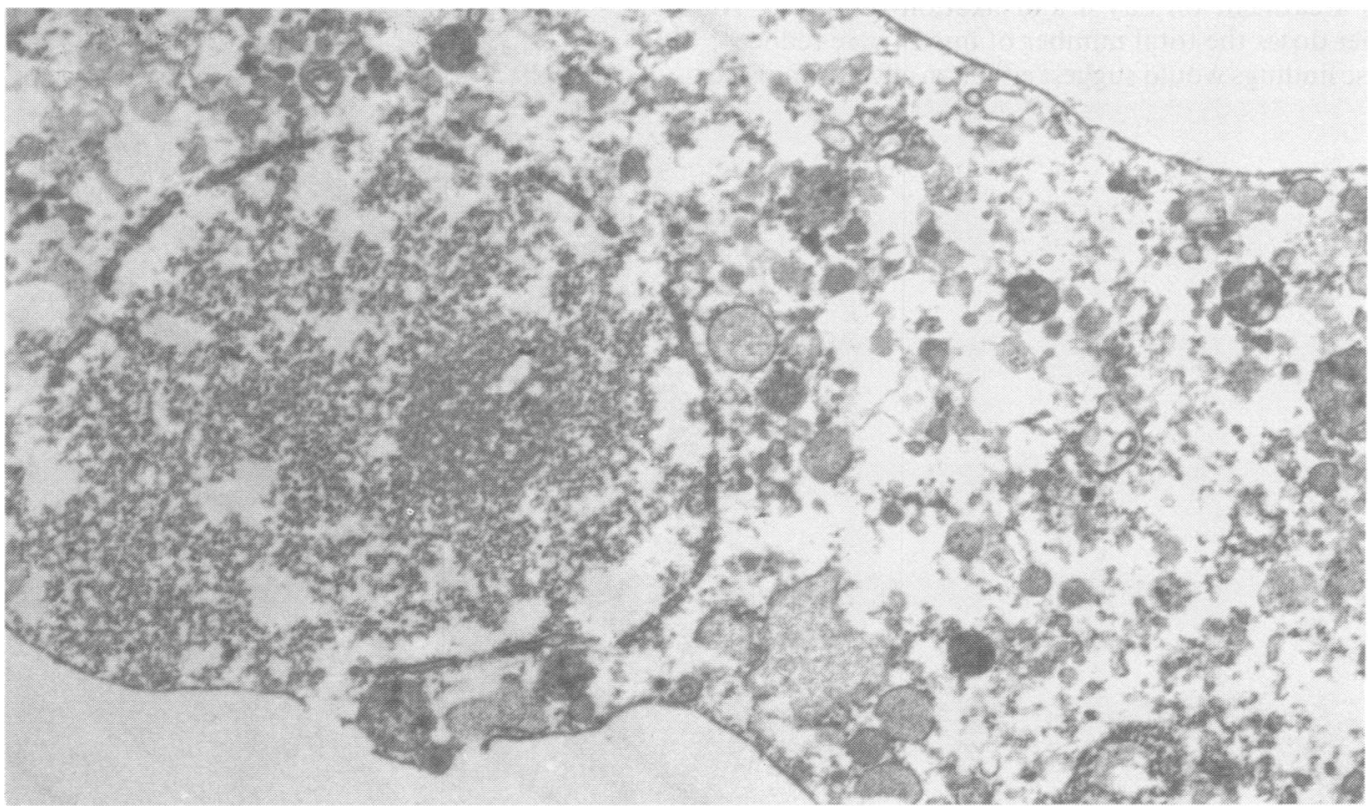

Fig 6 Electron micrograph of a culture treated with MIC (0.25 $\mu \mathrm{l} / 15 \mathrm{ml}$ culture) showing residual necrotic cell. $(\times 15000)$. 
the characteristic fibres of the muscle cells and the form of the endoplasmic reticulum of the fibroblasts (fig 2).

Cultures receiving $0.05 \mu \mathrm{l}$ MIC on day 4 were essentially the same as the controls at both the light and electron microscope level. At a treatment level of $0 \cdot 125 \mu \mathrm{l}$ MIC changes were observed. The syncytial muscle cells were much less abundant and necrotic cells were scattered throughout the culture (fig 3). At the electron microscope level the mononuclear cells could be identified as both myoblasts and fibroblasts. The myoblasts were less abundant than the fibroblasts and often had a simplified profile (fig 4). The fibroblasts were similar to the controls.

At the treatment level of $0.25 \mu \mathrm{MIC}$ all the cells of the culture were necrotic and there was no evidence of the syncytial muscle cells (figs $5 \& 6$ ).

\section{Discussion}

The results suggest that MIC is toxic for a mixed culture of fibroblasts and muscle cells but that the myoblasts appear to be more susceptible to the acute toxic action of MIC. Even at relatively low concentrations it was toxic. Lower doses tended to prevent myotube formation since the proportion of nuclei in myotubes was decreased at concentrations which had little effect on total number of nuclei as shown at doses of $0.125 \mu \mathrm{l}$ and $0.25 \mu \mathrm{l}$ after treatment on day 1 and fixation on day 5 and at a dose of $0.125 \mu \mathrm{l}$ and $0.25 \mu \mathrm{l}$ after treatment on day 4 and fixation on day 8 . At higher doses the total number of nuclei were reduced. These findings would suggest either an effect on muscle differentiation or selective toxicity to myoblasts. After treatment on day 6 effects were more severe because at this stage cells were detaching as monolayer sheets at the higher doses and both cell types appeared to be killed.

The importance of the findings for muscle tissue in the intact animal is not clear where muscle cells are under the control of the nervous system. It may be speculated that MIC would directly affect muscle tissue and prevent differentiation as shown in the in vitro situation. If MIC were also to directly attack the nervous tissue this might superimpose a lack of coordination in addition to a lack of differentiation.

\section{References}

1 Zaidi M. Bhopal and after. Am J Ind Med 1986;9:215-6.

2 Kimmerle R, Eben A. Zur Toxicität von Methylisocyanat und dessen quantitativer Bestimmung in der Luft. Arch Toxicol 1964;20:235-41.

3 Nemery B, Dinsdale D, Sparrow S, Ray DE. Effects of methyl isocyanate on the respiratory tract of rats. $\mathrm{Br} J$ Ind Med 1985;42:799-805.

4 Nemery B, Sparrow S, Dinsdale D. Methyl isocyanate: thiosulphate does not protect. Lancet 1985;ii: 1245.

5 Silver M, Germalec D, Vore S, Tucker A, Luster M. Immunotoxicology of methyl isocyanate in mice. The Toxicologist 1986;6:78. (Abstract No 311.)

6 National Toxicology Programme. Research Triangle Park, North Carolina: Department of Health \& Human Services, 1983:5-6. (Tech bulletin No 9.)

7 Shelby MD, Zeiger E, Caspary W, Mason J, Tice R. Genetic toxicity of methyl isocyanate (MIC). The Toxicologist 1986;6: 78. (Abstract No 312.)

8 Anderson D, Blowers SD, Nemery B. Investigation of the Ames test of urine samples from rats exposed to methyl isocyanate. $\mathrm{Br}$ J Ind Med 1986;43:566-7. 